\title{
ANODIC COATINGS FOR TEMPERATURE CONTROL IN SPACE VEHICLES
}

\author{
E. W. Cooké and W. L. Long \\ Missile Division \\ North American Aviation, Inc.
}

\section{INTRODUCTION}

The importance of surface radiation characteristics in controlling the internal temperature of space vehicles has been comprehensively reviewed by other investigators 1 . It is imperative that extraterrestrial vehicles now in design be provided a surface with a ratio of solar absorptance (alpha) to long wavelength emittance (epsilon) equal to about 0.15 to 0.18 . Ideally, a surface should possess an alpha of 0.10 and an epsilon of 0.9 , or an alpha-to-epsilon ratio of 0.11 .

The low alpha and high epsilon are properties which are given for magnesium oxide radiation standards. These standards are produced by burning magnesium and collecting the oxide; however, the oxide thus formed is difficult to apply and too fragile for practical application on operating space vehicles. The anodizing of magnesium was attempted at the Missile Division but funding was limited and other processes appeared extremely promising; therefore, in this initial investigation, only limited effort was directed toward the production of magnesium oxide.

Camack and Edwards ${ }^{2}$ have indicated polished metals sheathed with transparent coatings among various surfaces which would remain relatively cool in the solar radiation of space. Drummeter and Goldstein ${ }^{3}$ have described the polished and coated aluminum surfaces considered for the Vanguard satellites. Pure aluminum oxide is considered transparent to radiation in the visible region. Since polished aluminum is a good reflector at all wavelengths between 0.2 and 20 microns, a transparent anodic coating for aluminum was favorably considered as an interim coating. This paper reports the progress on the attempts made to develop coatings on aluminum and magnesium with sufficiently low alpha-to-epsilon ratios.

\section{DISCUSSION}

Several types of temperature control systems were evaluated at the beginning of this investigation. Paints containing various pigments were given special consideration because of their inherent ease of application. However, the possibility of pigment discoloration and evaporation of the 


\section{Report Documentation Page}

Form Approved

OMB No. 0704-0188

Public reporting burden for the collection of information is estimated to average 1 hour per response, including the time for reviewing instructions, searching existing data sources, gathering and maintaining the data needed, and completing and reviewing the collection of information. Send comments regarding this burden estimate or any other aspect of this collection of information,

including suggestions for reducing this burden, to Washington Headquarters Services, Directorate for Information Operations and Reports, 1215 Jefferson Davis Highway, Suite 1204, Arlington

VA 22202-4302. Respondents should be aware that notwithstanding any other provision of law, no person shall be subject to a penalty for failing to comply with a collection of information if it

does not display a currently valid OMB control number.

\begin{tabular}{|c|c|c|}
\hline $\begin{array}{l}\text { 1. REPORT DATE } \\
\mathbf{1 9 6 0}\end{array}$ & 2. REPORT TYPE & $\begin{array}{l}\text { 3. DATES COVERED } \\
\mathbf{0 0 - 0 0 - 1 9 6 0 ~ t o ~ 0 0 - 0 0 - 1 9 6 0 ~}\end{array}$ \\
\hline \multirow{3}{*}{\multicolumn{2}{|c|}{ Anodic Coatings for Temperature Control in Space Vehicles }} & 5a. CONTRACT NUMBER \\
\hline & & 5b. GRANT NUMBER \\
\hline & & 5c. PROGRAM ELEMENT NUMBER \\
\hline \multirow{3}{*}{\multicolumn{2}{|c|}{ 6. AUTHOR(S) }} & 5d. PROJECT NUMBER \\
\hline & & 5e. TASK NUMBER \\
\hline & & 5f. WORK UNIT NUMBER \\
\hline \multicolumn{2}{|c|}{$\begin{array}{l}\text { 7. PERFORMING ORGANIZATION NAME(S) AND ADDRESS(ES) } \\
\text { Wright Air Development Center,Wright Patterson AFB,OH,45433 }\end{array}$} & $\begin{array}{l}\text { 8. PERFORMING ORGANIZATION } \\
\text { REPORT NUMBER }\end{array}$ \\
\hline \multirow{2}{*}{\multicolumn{2}{|c|}{ 9. SPONSORING/MONITORING AGENCY NAME(S) AND ADDRESS(ES) }} & 10. SPONSOR/MONITOR'S ACRONYM(S) \\
\hline & & $\begin{array}{l}\text { 11. SPONSOR/MONITOR'S REPORT } \\
\text { NUMBER(S) }\end{array}$ \\
\hline
\end{tabular}

12. DISTRIBUTION/AVAILABILITY STATEMENT

Approved for public release; distribution unlimited

13. SUPPLEMENTARY NOTES

14. ABSTRACT

see report

15. SUBJECT TERMS

16. SECURITY CLASSIFICATION OF:

a. REPORT

unclassified b. ABSTRACT

unclassified c. THIS PAGE

unclassified
17. LIMITATION OF ABSTRACT

\begin{tabular}{|c|l|}
\hline $\begin{array}{c}\text { 18. NUMBER } \\
\text { OF PAGES } \\
\mathbf{1 8}\end{array}$ & 19a. NAME OF \\
& \\
&
\end{tabular}


organic base in the space environment were considered to be decided disadvantages, particularly during long space missions. Inorganic oxides such as those of aluminum and magnesium, which can be formed as an inherent part of the base material, are promising as interim coatings.

\section{Magnesium Oxide}

The unusual radiation properties of smoked magnesium oxide will not be discussed at length in this paper; however, index of refraction, crystal size, and configuration are probably some of the factors involved in this case. Although duplication of this surface by electrochemical means appears possible, the difficulties in producing white coatings limited this investigation to the modification of well-developed processes.

Three well-known commercial anodic treatments for magnesium were modified by eliminating compounds which would deposit colored ions on the surface. While temperature and concentration remained unchanged, voltage and current density were modified under some conditions. Coatings did not form upon samples processed in two of the baths. However, a white coating did form on samples which were processed in one bath. This success was attained in the HAE bath which was modified to remove ions producing colored residues. Conditions and operating variables are given in Table 1 . The coatings appeared dull white. The radiation measurement upon a typical coating is given in Figure 1 . These results indicate that much improvement will be necessary before this type of coating can be considered for space applications.

Table 1. White HAE Magnesium Anodizing Solution

$$
\begin{gathered}
120.0 \text { grams/liter } \mathrm{KOH} \\
10.5 \text { grams/1iter } \mathrm{Al} \\
35.5 \text { grams/1iter } \mathrm{KF} \cdot 2 \mathrm{H}_{2} \mathrm{O} \\
35.0 \text { grams/1iter } \mathrm{Na}_{3} \mathrm{PO}_{4} \\
\text { Remainder } \mathrm{H}_{2} \mathrm{O}
\end{gathered}
$$

\section{Aluminum Oxide}

Richmond $^{4}$ has reviewed the general emittance properties of materials. He noted that the emittance of a transparent coating is partly influenced by the substrate material, depending upon coating thickness. Therefore, polished aluminum with a transparent coating of aluminum oxide is expected to possess a lower alpha-to-epsilon ratio than either polished aluminum or aluminum oxide. This is a double surface effect because the polished aluminum reflects the solar radiation which is 
permitted to traverse the aluminum oxide coating. The oxide coating of sufficient thickness is opaque in the long-wavelength infrared region. Therefore, infrared is emitted in much the same manner as gross aluminum oxide.

There are at least two commercial uses for polished and anodized aluminum 6,7 . While visual reflectance is the criterion for commercial applications, valuable data relative to alloy and polishing techniques were gained. High-purity aluminum alloy was necessary before extremely transparent coatings could be produced.

About 2 percent magnesium may be alloyed with aluminum if strength is required; however, other impurities must be limited to 0.02 percent or less for satisfactory reflectance. The most commonly used process for polishing high-purity aluminum is given in Table 2. (This process is a European development and is used primarily for polishing automobile bumpers.) The electropolishing solution is shown in Table 3. This solution is one of the outstanding features of the process, and was adopted for this investigation. Another solution which was evaluated as an alternate is listed in Table 4. Both processes produce excellent mirror finishes, but, the solution from Table 3 is preferred because it presents no explosion hazard. Special precaution has to be taken in the operating solution shown in Table 4 because it does present an explosion hazard.

The best anodizing solutions were saturated boric acid and 10 to 15 percent sulfuric acid. Although 15 percent sulfuric acid solution produced bright coatings, they were easily scratched and stained. Consequently, the concentration was reduced in an effort to alleviate this condition. It is assumed that harder surfaces will be produced by reducing temperature; however, decreasing the temperature will be conducted after radiation measurements are completed on other parameters. A high-purity aluminum cathode to prevent solution contamination was necessary because a contaminated solution appears to impair the surface of the sample.

Two aluminum alloys were used, 1199 and Reflectal. A commercial product, 1199 aluminum contains less than 0.02 percent impurities. Reflectal is a commercial European alloy with about 1.5 percent magnesium and 0.02 percent impurities. Coupons were processed to a mirror or bright satin finish.

\section{Measurements}

Arrangements were made with two reputable laboratories to perform radiation measurements which would give an indication of solar reflectance and room temperature emittance. Total normal spectral reflectance from 0.4 to $15 \mathrm{micr}$ ons was measured by one laboratory. Two measurements were made by the other laboratory: total hemispherical emittance at $95^{\circ} \mathrm{C}$; 
Table 2. Bright Anodizing Process

Mechanical polish

Brytal electropolish

Mechanical polish

Sulfuric acid anodize

Table 3. Brytal* Electropolishing Solution

$$
\begin{aligned}
& \text { 30. } 0 \% \mathrm{Na}_{2} \mathrm{CO}_{3} \\
& \text { 6. } 5 \% \mathrm{Na}_{3} \mathrm{PO}_{4} \\
& 3.0 \% \text { Rochelle salt } \\
& 60.5 \% \mathrm{H}_{2} \mathrm{O} \\
& 175-195 \mathrm{~F} \\
& 70-80 \mathrm{amp} / \mathrm{sq} \mathrm{ft} \\
& 30 \mathrm{~min}
\end{aligned}
$$

*British Aluminum Co. trademark

Table 4. Jacquet Electropolishing Solution

$35 \%$ (vol) perchloric acid $\left(50 \% \mathrm{HClO}_{4}\right)$

$65 \%$ (vol) acetic anhydride

$$
\begin{aligned}
& 40-60 \mathrm{~F} \\
& 26 \mathrm{v} \\
& 15 \mathrm{~min}
\end{aligned}
$$

and spectral reflectance within an integrating sphere from 0.3 to 3.4 microns. Representative results are shown with varying conditions in Figures 2 through 11 . Poor reflection and emittance are shown for anodized magnesium (Figure 9). Figures 10 and 11 show the reflectance for polished aluminum which was not anodized. All curves are representative of samples which were prepared by each specific process. Data from five samples provide encouraging results and are summarized in Table 5. 
Table 5. Summary of Data

\begin{tabular}{|c|l|l|l|c|}
\hline $\begin{array}{c}\text { Sample } \\
\text { No. }\end{array}$ & Alloy & Alpha* & Epsilon* & $\begin{array}{c}\text { Alpha-to-Epsilon } \\
\text { Ratio }\end{array}$ \\
\hline 34 & Reflectal & 0.2 & 0.8 & 0.25 \\
35 & Reflectal & 0.2 & 0.8 & 0.25 \\
36 & Reflectal & 0.2 & 0.8 & 0.25 \\
38 & Reflectal & 0.15 & 0.75 & 0.20 \\
58 & 1199 & 0.15 & 0.74 & 0.20 \\
\hline *Approximate & & \\
\hline
\end{tabular}

Met:allographic study of the anodic coating produced by the 15 minute, room temperature process in $10 \%$ sulfuric acid on polished Reflectal. alloy, gave a thickness of 12 microns. A thickness of about 4 micorins had been anticipated from information contained in pertinent literature. An interesting problem which will be resolved in future work is the variation of emittance with the coating thickness. Boric acid anodizing produces a film thickness of about 13 angstroms per volt after a few seconds. Experience in handling these anodic coatings has indicated that storage and handling must be effected with great care.

\section{CONCLUSION}

These are a portion of the results of a 1 -year investigation by the Missile Division Laboratory of North American Aviation, Inc. This investigation is being continued until conditions can be established for producing the optimum aluminum oxide. While the best alpha-to-epsilon ratio reported herein is 0.20 , it is felt that by modifying temperature and concentration of the anodizing solution, a lower value can be attained. After the optimum ratio has been attained, more effort will be directed toward theoretically superior coatings such as magnesium oxide and zirconium oxide.

Great care must be exercised in handling and storing these materials. Fingerprints, oil scratches, and dust, will alter their radiation properties. Therefore, some effort will be directed toward developing a coating which can protect a space vehicle surface until launch. These coatings can be removed just prior to launch, or a coating can be applied which provides adequate mechanical properties during storage but which will evaporate in the conditions of outer space. However, the coating must possess characteristics which do not impair the radiation properties of the surface after removal. 


\section{REFERENCES}

1. Clauss, F.J. (Editor), "Surface Effects on Spacecraft Materials," Wiley, 1960.

2. Camack, W. G., and Edwards, D. K., "Effect of Surface ThermalRadiation Characteristics on the Temperature Control Problem in Satellites, "p. 29 of Reference 1.

3. Drummeter, L. F., Jr., and Goldstein, E., "Vanguard Emittance Studies at NRL," pp. 157-161 of Reference 1.

4. Richmond, J.C., "Coatings for Space Vehicles," pp. 93-95 of Reference 1.

5. "Metal Finishing Guidebook-Directory," Metals and Plastics Publications, 1960.

6. "46th Annual Technical Proceedings," American Electroplaters Society, 1959.

7. Wernick, S., and Pinner, R., "Surface Treatment of Aluminum and its Alloys, "Robert Draper, 1956. 


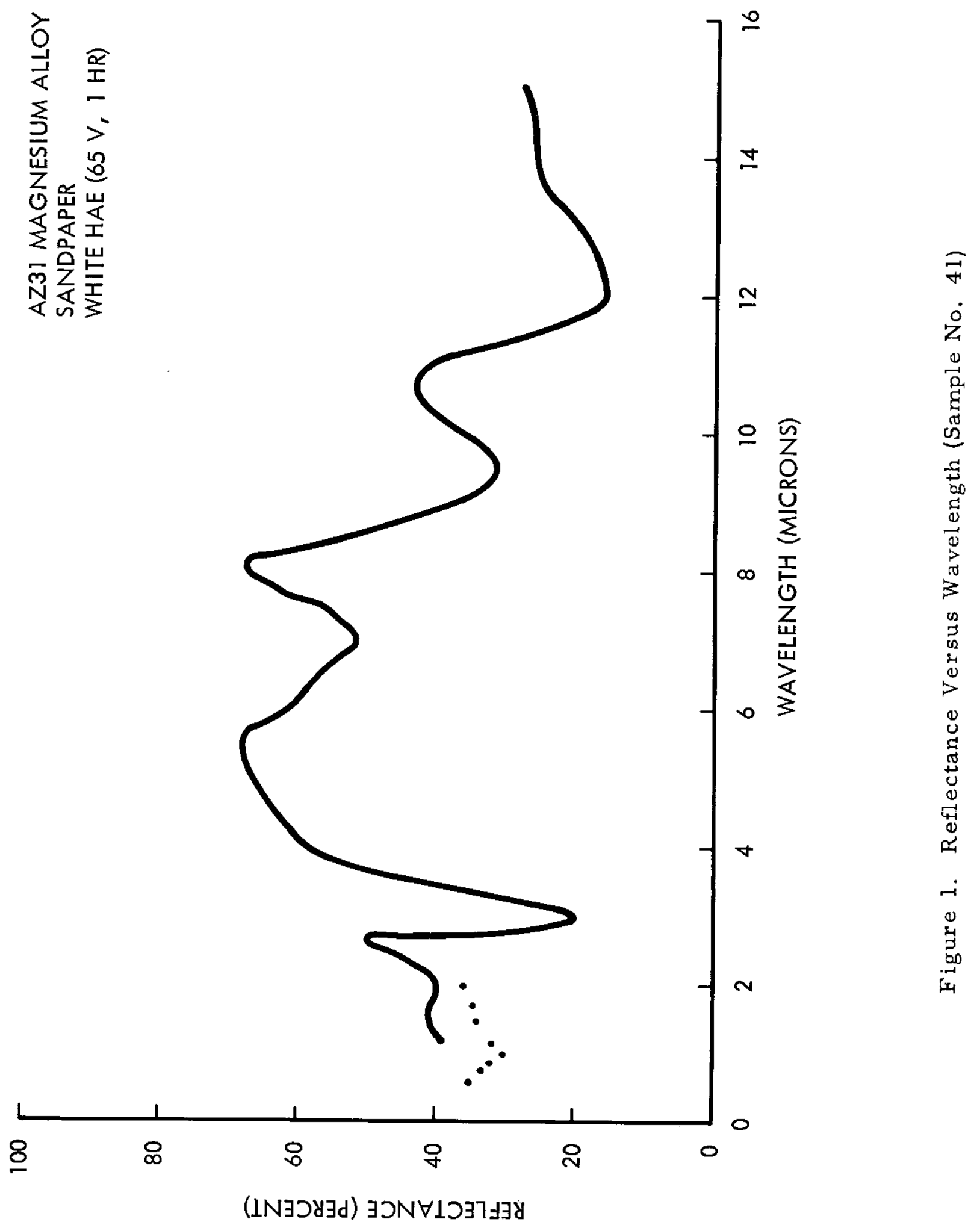




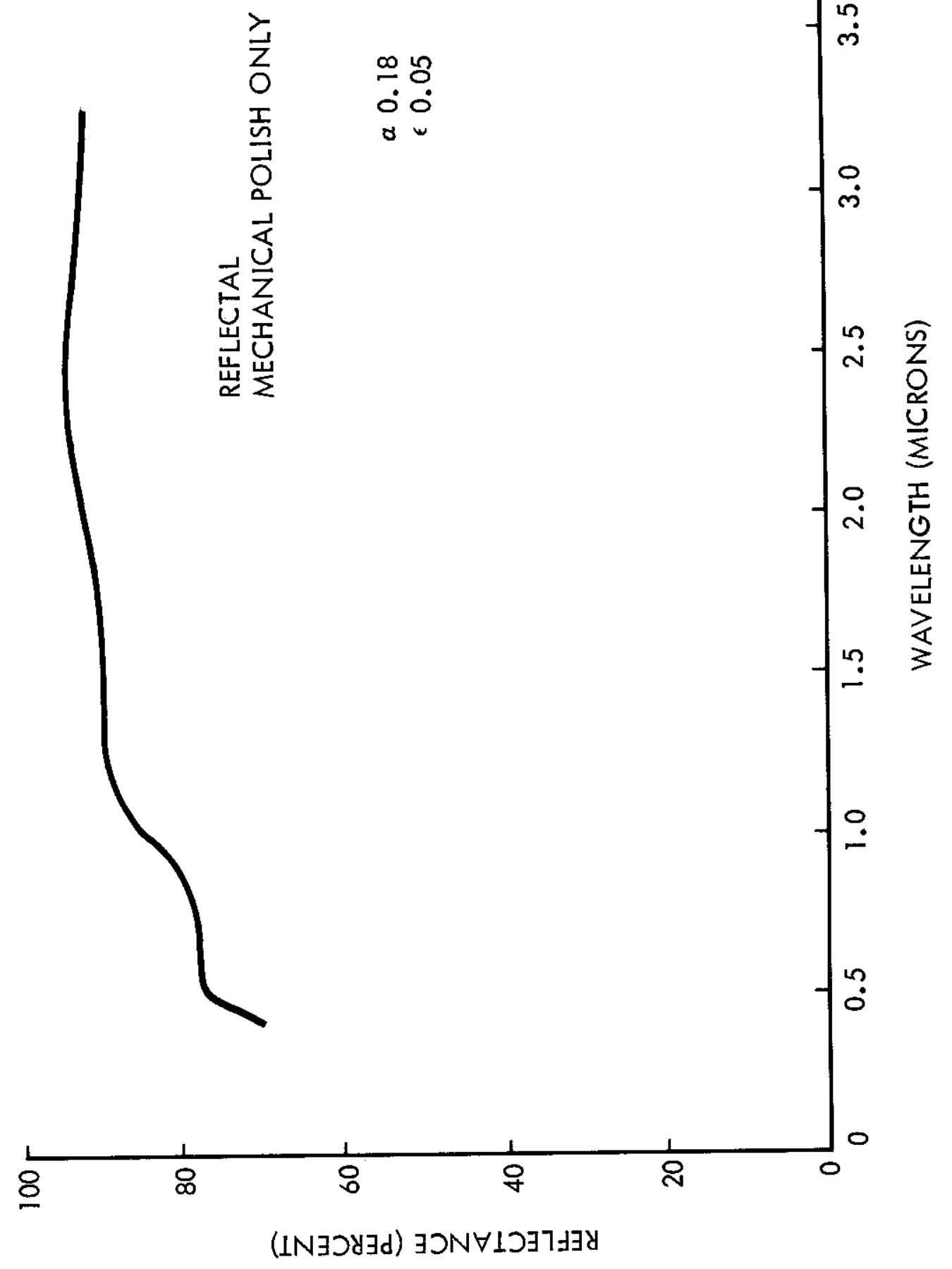




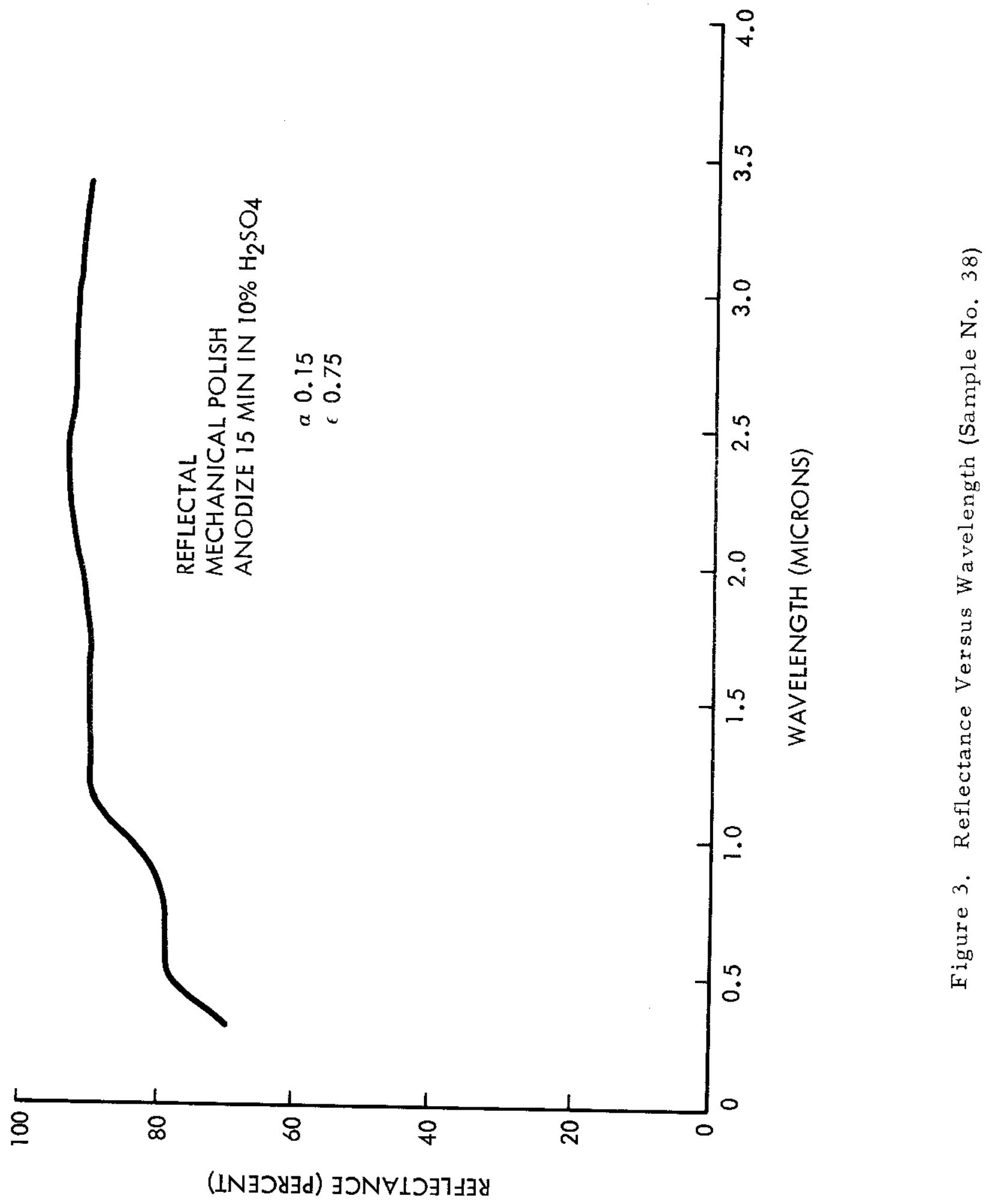




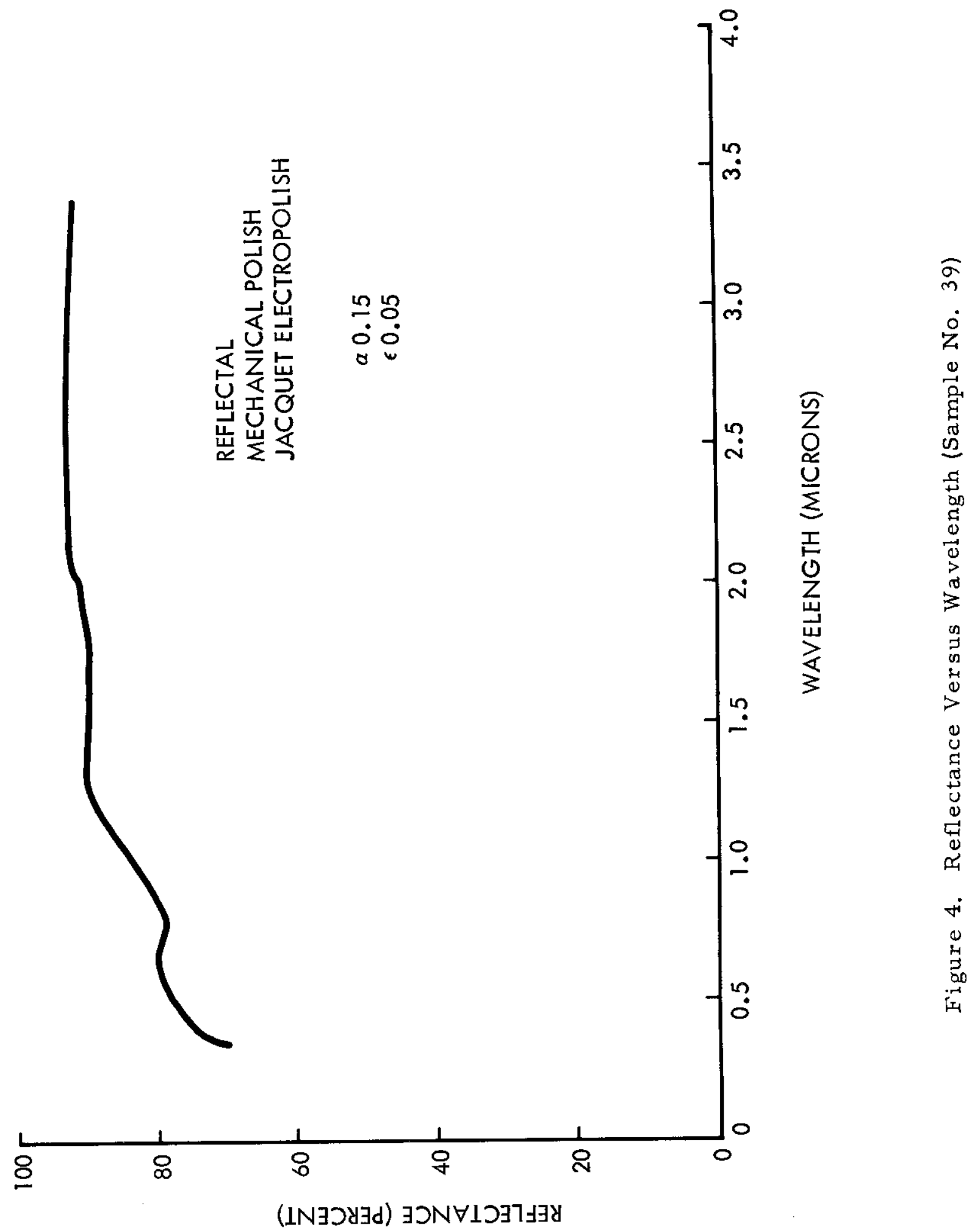

WADD TR $60-773$ 


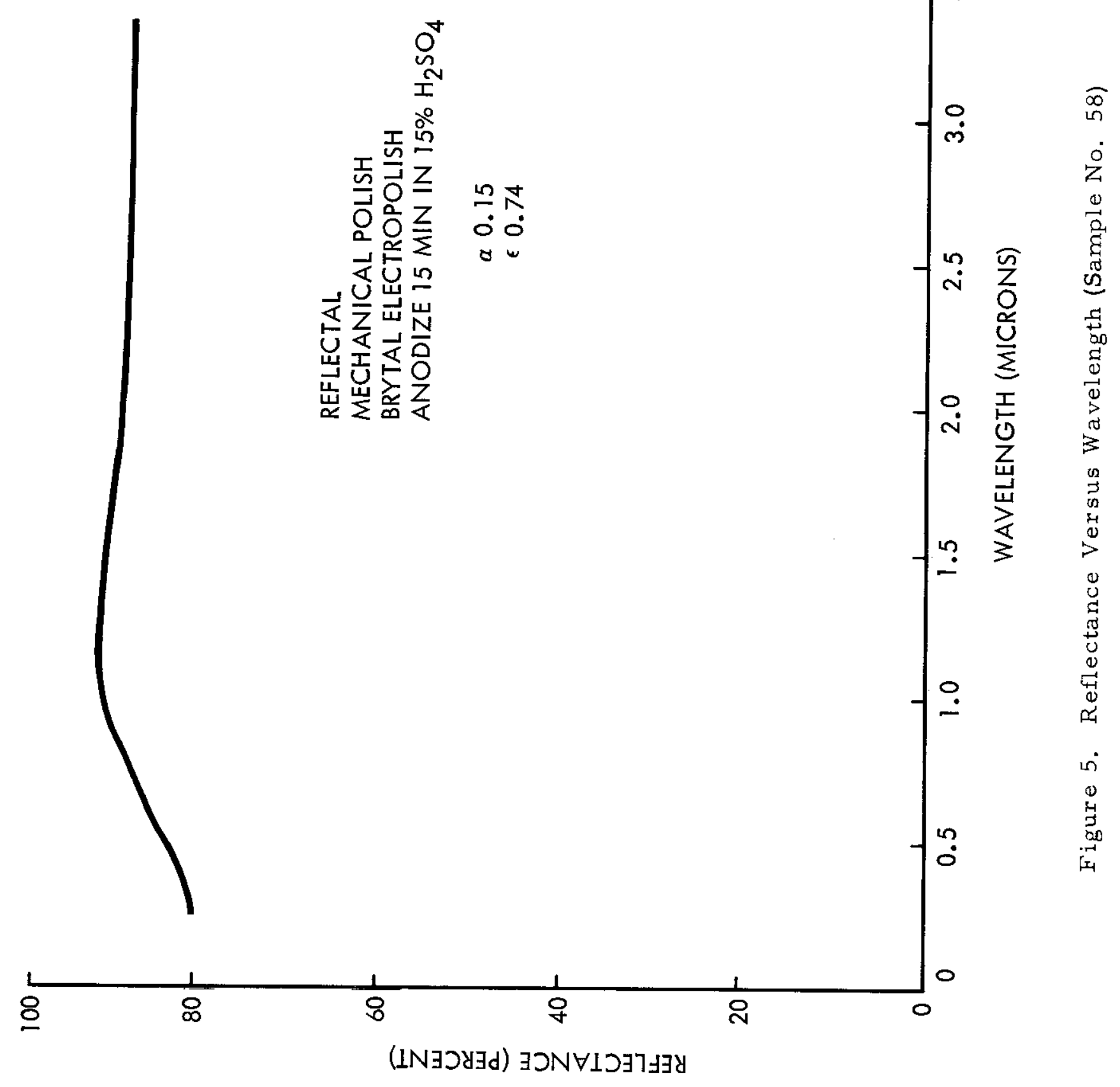




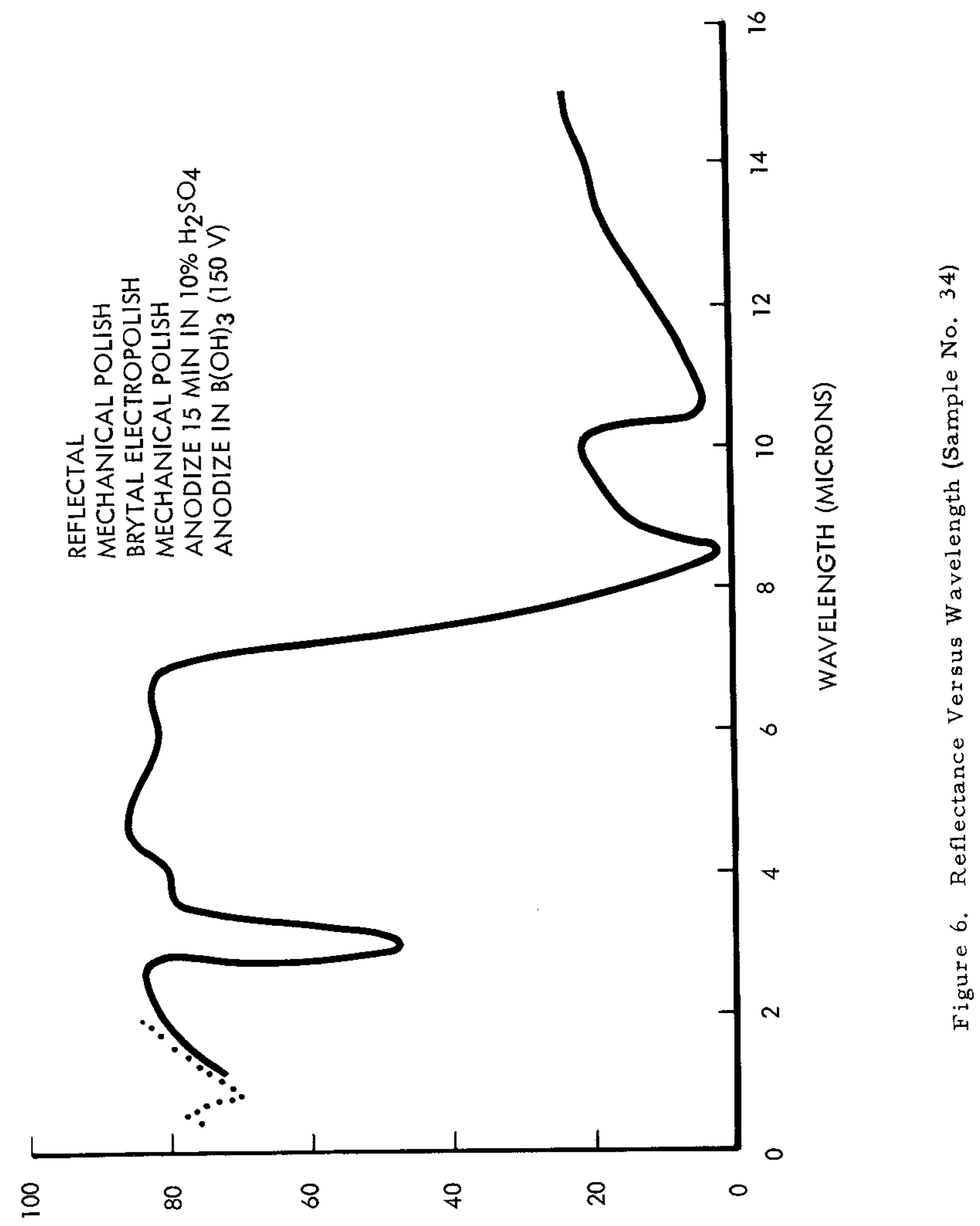

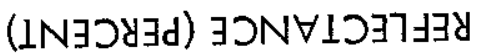




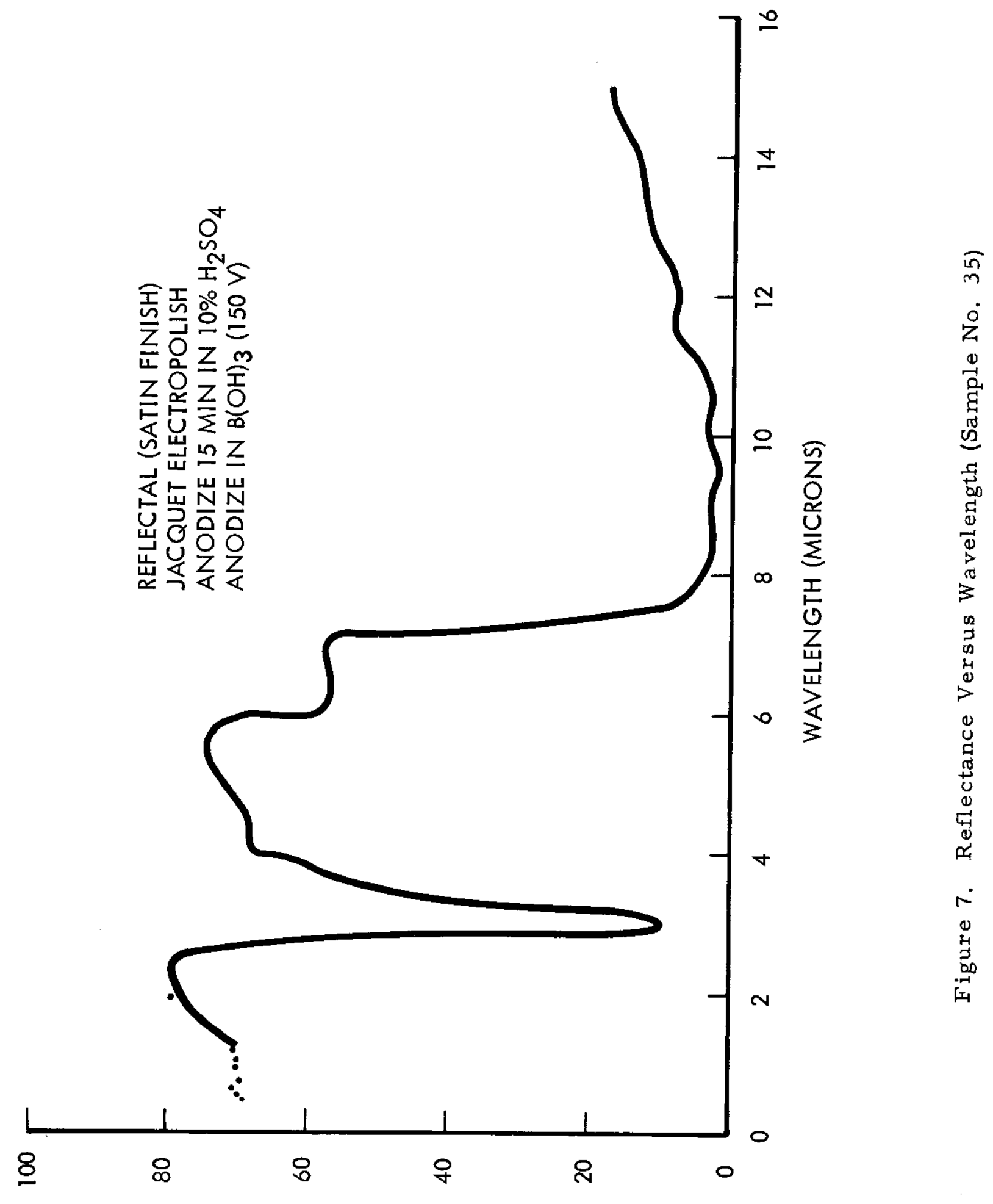

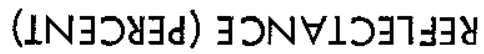




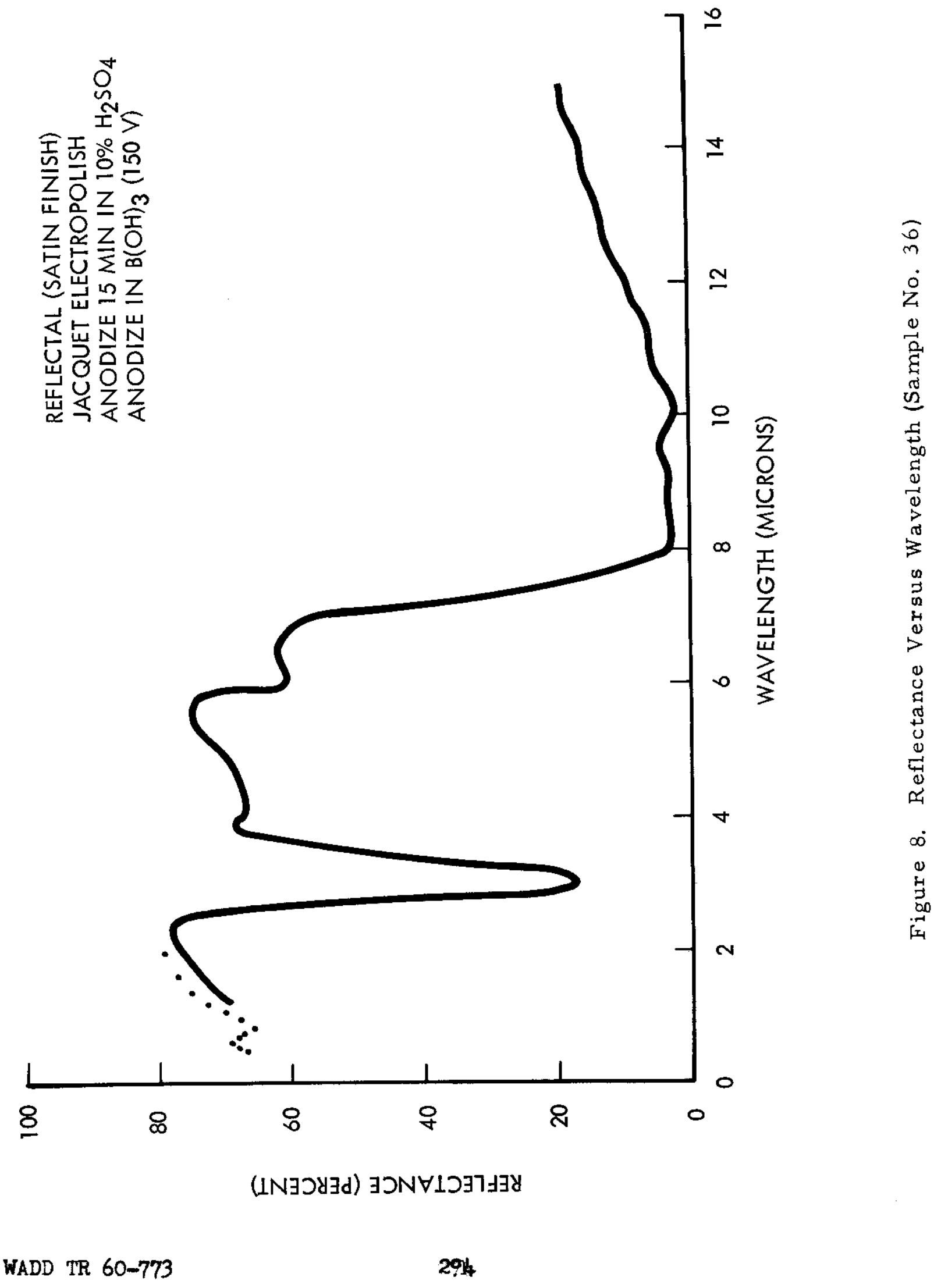




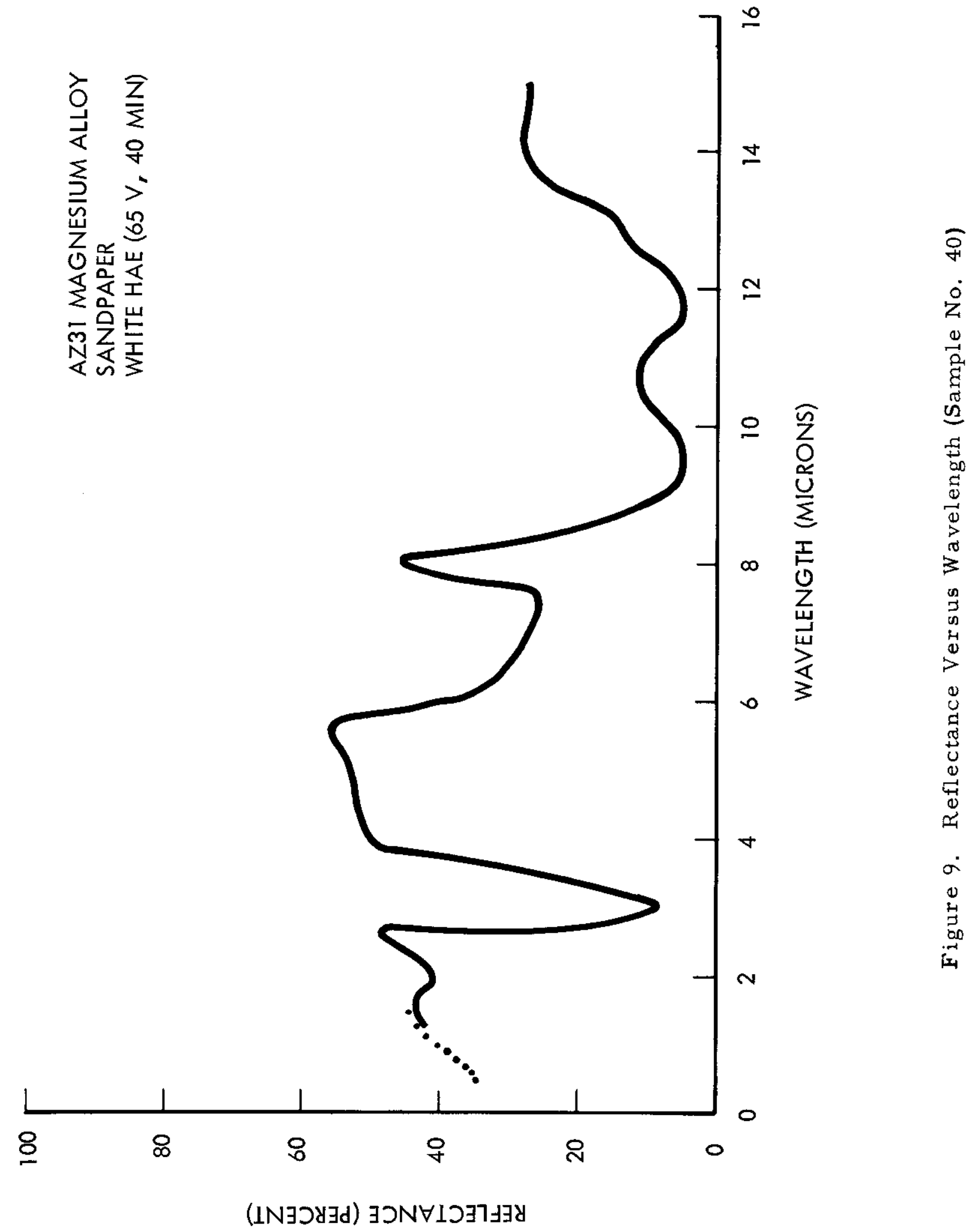

WADD TR 60-773 


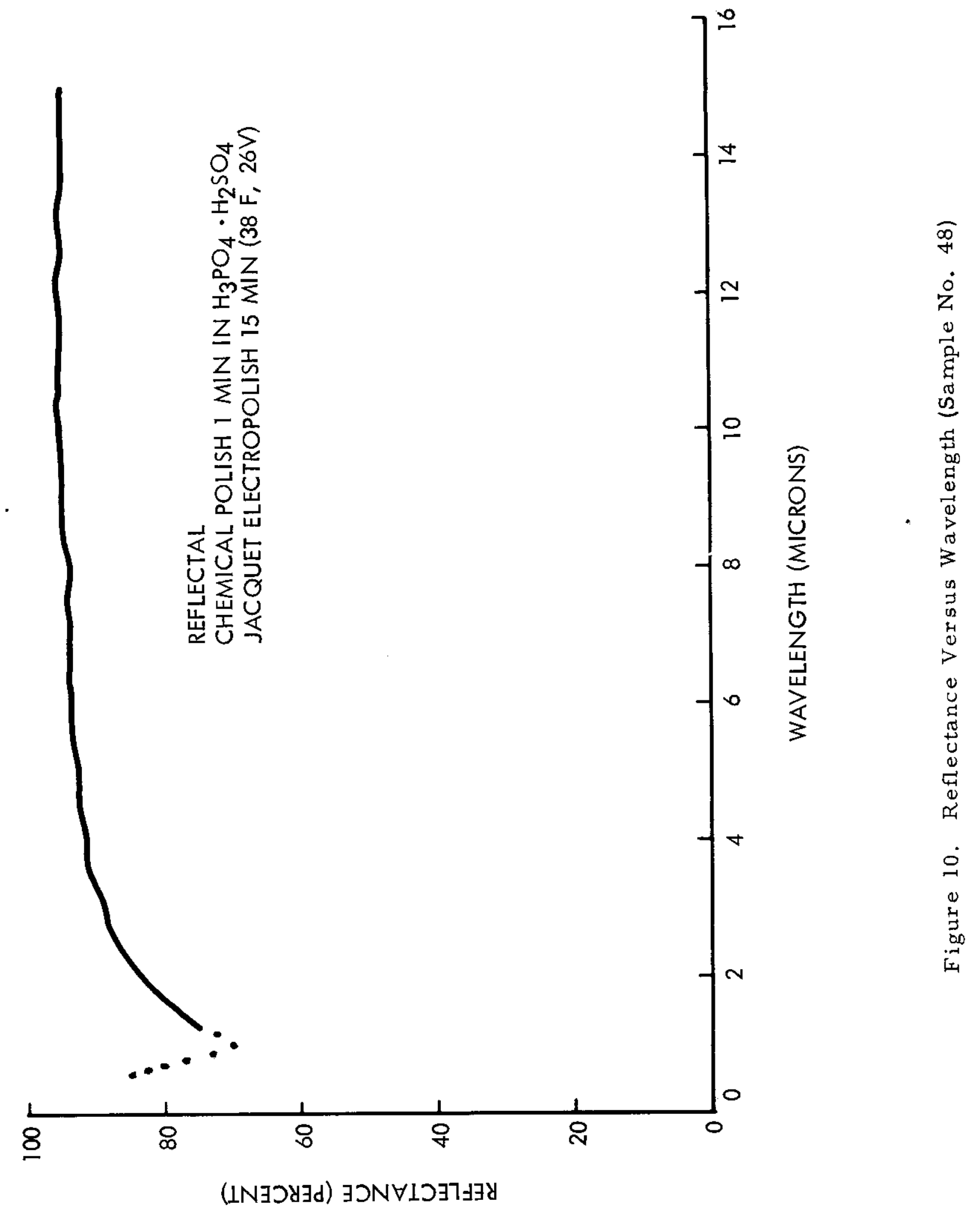

WADD TR 60-773 


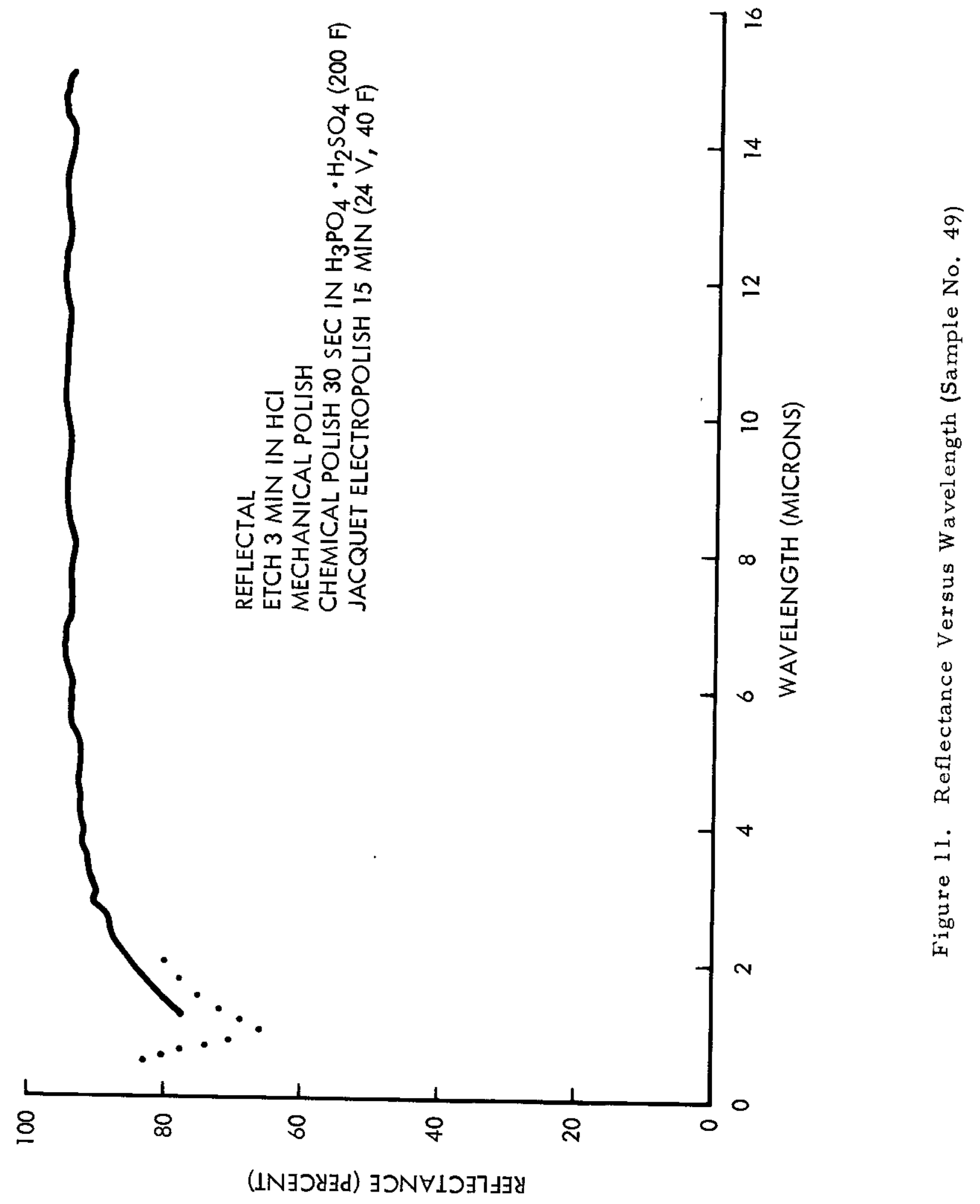

WADD TR 60-773 
